occurred in about ten minutes. An atmosphere containing one per cent. of the gas was found to prove fatal within half an hour. In the case of a large female rabbit, $0^{\prime} 2$ per cent. caused death in thirty-three minutes. In these cases the most marked symptom was that of great increase in the number of respirations. Before death, respiration became slow and laboured, and convulsions resembling those of opisthotonus occurred. The ventricles of the heart became most powerfully contracted. Where the strongest dose was administered, the effect on the heart was most marked, and the lungs appeared unaffected. When small quantities of the gas were used, within a very short time the animals began to show signs of suffering from intense irritation of the skin, scratching and biting at it incessantly. Afterwards the creatures seemed to become drowsy, and assumed a very peculiar attitude, sitting down on all-fours, the back bent upwards, and nose pushed backwards between the fore-paws, so as to bring the forehead against the floor of the cage ; a rat in this position looked very much like a curled-up hedgehog. A fatal result occurred when the quantity of gas was so small as $I$ to 5120 . In no case could the odour of the gas be detected in any organ of the body after death. The gas did not appear to exert any local action on the skin.

STRUCTURE AND AFFINITIES OF CHARACE⿸广. - This difficult problem has been the subject of recent discussion in the pages of Trimen's Fournal of Botany. The first paper was in the July number, by Mr. A. W. Bennett, who gave his reasons for dissenting from some generally accepted views of the structure of Chara, and from its assignment by Sachs to a place among the Carposporeæ. He objects in the first place to the use of the term "proembryo"i(Vorkeim) for the immediate product of the germination of the spore, the homologue of the protonema of a moss, and not of the pro-embryo nor suspensor of Sclaginellaceæ and Phanerogams. The term sporangium is also frequently misapplied to the nucule, which is in reality an archegonium. The so-called "sporocarp" is formed before and not as the result of fecundation. Finally, Mr. Bennett maintains that Characeæ differ from all the other higher cryptogams in the absence of any alternation of generations, the nearest affinity being with Muscinex, which they approach in their organs of reproduction. In the September number Prof. Caruel expresses his agreement with Mr. Bennett in removing the Characeæ from the Carposporeæ, but differs in his interpretation of the structure which is the immediate product of germination, the homology of which with the protonema of mosses he contests. He places them in a separate class of their own, intermediate between phanerogams and vascular cryptogams. Finally, in the number for December, Mr. S. H. Vines has a very elaborate essay on the subject. He agrees with both the previous writers in separating the Characeæ from the Carposporeæ, and with Caruel in disputing the homology of the "pro-embryo" with the protonema of a moss, but on the other hand again considers their nearest affinity, though remote, to be with Muscineæ. His principal object is to show that the "pro-embryo" is in reality the embryo of the plant, and that it constitutes in itself the non-sexual generation or sporophore, homologous with the sporogonium of mosses, notwithstanding the apparently anomalous fact that it never produces spores. For such a structure he proposes the term "aposporous sporophore," and compares it to the "apogamous" oophore or prothallium of Pteris cretica and some other ferns, which are anomalous in not producing sexual organs of reproduction.

GEOGRAPHICAL NOTES

THE fifty-sixth supplement to Petermann's Mittheilungen has just been published, and consists of a masterly. treatise on.Deltas, by Dr. G. A. Credner, of Halle. The author shows the importance of deltas in reference both to geographysand geology, and discusses carefully the real import of the term. He then, in the first part of his work, treats of the Formation, Structure, Growth, and Distribution of Deltas under the heads of (I) Limit and Form of the Delta; (2) Formation and Condition of the Delta Surface; (3) Size of the Delta; (4) Its Power; (5) Its material; (6) Architecture; (7) Rate of its Growth; (8) Results of its Growth; (9) The Age of Deltas; (Io) Number and Geographical Distribution of Deltas; (Ir) Classification of Deltas. The second part treats of the various causes of the origin of deltas, the causes and conditions of their formation, in which the author discusses various processes of great geological interest. Three sheets of maps accompany this most important paper, showing, among other points, the various deltas of the world.

WE are glad to learn of the early appearance of a work published in Russia under the editorship of $M$. Semenoff, President of the Geographical Society at St. Petersburg: The title is "Illustrated Russia," and it will give a geographical, historical, ethnographical, and statistical description of the country. We notice among the very numerous collaborators all the names well known in the Russian geographical world. The work will contain four folio volumes of sixty to seventy sheets each, and it will be accompanied with numerous illustrations, engraved by the best European firms. Another work of the same kind is undertaken by M. Mordovtseff-"The Ukraine (Little Russia) : its History and its People." It will be on the same plan as the well-known work on "Bohemia: its History and its People."

WE are also glad to notice the appearance of the last volume of the "Works of the Ethnographical Expedition sent by the Russian Geographical Society." This volume deals with the south-western provinces of Russia. The expedition was undertaken in 1869 , finished in two years, and the printing of the reports, which occupy seven large volumes, has taken since 1872 .

We find in the Izvestia of the Russian Geographical Society a notice of the journey of M. Mayeff in Southern Bokhara, last August. After having reached Karshi with an embassy sent to the Emir by the Governor-General of Tashkent, M. Mayeff visited the mountain pass, Ak-bash, which goes from Tenga-kboram to the Kerchak River, and to the great and wealthy village, Kuitan: thrnce he proceeded by the pass Tenga-daval to Shir-abad. The Kerchak River and its tributary, Kuitan-daria, both mighty mountain streams, were previously quite unknown. The Tenga-daval cleft cuts through the whole mass of the Kuityn-tau, the south-western part of Hissar ridge. From Shir-abad M. Mayeff, going further south, crossed the great Pashkbund ridge, reached the Surkhan river at Kakaity, and traced its banks down to Regar and Sarydjuy. Thence he returned to Shahri-sabs by a very bad route, hardly practicable even on horseback, along the rocky banks of the wild stream, Sengri-dagh. The surveys made during this journey are a most important acquisition for the geography of Central Asia ; the highlands of Bokbara, quite unknown until now, will soon receive on our maps an outline in accordance with nature.

THE last number of the Izvestia of the Russian Geographical Society contains a report, by Capt. Sidensner, on the possibility of a water communication between the tributaries of the $\mathrm{Obi}$ and Yenissei ; a very interesting paper, by M. Miclucho Maclay, on the Pelew archipelago, being a description of the people, its customs, administration, and religion; a necrology of $\mathrm{M}$. Chaslavsky; and several notes:-On M. Mayeff's journey to Southern Bokhara, on the Russian cruises to the Obi and Yenissei, and especially statistical ones on printing in Moscow, on trade, ports, and telegraphs in Japan, and on the population and manufactures in governments Tula and NijniNovgorod. 
DR. EDWIN R. HEATH, to whom we referred some time ago as intending to take up the work of South American exploration commenced by Prof. Orton, and interrupted by his untimely death, left New York on November 18, on the William $H$. Keeney, for Pará, expecting to proceed by steamer to San Antonio, to remain there during the winter, and from that point as a centre to carry on his further investigations. In these he expects to be greatly assisted by Messrs. T. and P. Collins, of Philadelphia, the contractors for the Mamore and Madera Railroad.

THE Woodruff half-educational, half-pleasure expedition round the world has been again organised on a new basis. A steamer of 3,000 tons has been purchased in Europe, and the inclusive fare is 2,500 dollars.

MR. S. E. PEAL communicates to the Indian Tea Gazette some remarks on the subject of an overland route to China, via the Assam Valley, which are of interest, as there is no attempt to under-rate the great difficulties to be encountered. He justly observes that the merits of the various passes out of Eastern Assam are not well understood, and that it is comparatively easy to draw a line on the map from some point in Upper Assam to the Yangtoze or Likiang-fu, and to say, "Why cannot this be done?" Wilcox and others since have sufficiently shown the difficult nature of the country, via the Tengapani and the Brahmaputra Valley; what lies beyond the point explored is reputed still worse, and as crossing snow. Northwards again, viâ the Dihong, or Dihong Gorges, the outlet is equally uninviting. The Upper Subansire, or Lopra-cha-chu, is not well explored, though routes not far from it are known to pass for threequarters of a mile along the face of a precipice 1,500 feet above an abyss, and on a path of stone slabs resting on iron piers let into the face of the rock. The Towang route is, again, difficult, and too far west. South of the Tengapani we have Dapha Búm, I4,500 feet high, with a pass to the south, in which Wilcox's experiences prove how unsuitable it would be for a trade-route. "South of Daphapani is the upper portion of the Buri Dihing, and whether there is a route up it crossing Eastern Patkai and going down the Sitka, is not known, though Singphús travel that way. It is one of the routes to be explored, and may give a pass at, perhaps, 5,000 feet elevation or less. The Namrup basin, however, would so far seem to be the only reliable and easy outlet from Eastern Assam : and here is a pass at an elevation of about $\mathrm{I}, 000 \mathrm{ft}$., leading viâ Hukong and the Shoemai direct to Western Yünnan, a route which is at present in use. By the Patkai route past Nongyang Lake to the Hukong Valley, Mr. Peal says, we cross at the highest an elevation of 1,500 to $2,000 \mathrm{ft}$., and fall at once into $a$ beaten track to Yünnan. By this route alone also can the huge snow-clad ridges be turned that stand as barriers east and west of the Upper Irrawadi or Shoemai, and that stretch down from the north to about the parallel of $27^{\circ}$. In point of fact the east-south-east is the only direction in which it is possible to get out of Assam in the direction of China at less than 2,000 ft. above the sea-level.

\section{THE COMPOUND NATURE OF THE}

\section{ELEMENTS}

WE have not yet received from the Royal Society the N. paper read last Thursday by Mr. Lockyer, in which he brought forward facts indicating the compound nature of the chemical elements. In the meantime the following article from yesterday's. Times may be of interest; it is evidently written by a chemist who was present when the paper was read :-

"At a crowded meeting such as is seldom witnessed of the Royal Seciety, on Thursday evening last; Mr. J. Norman Lockyer, F.R.S., read a lengthy paper, in which he discussed the evidence derived from spectroscopic observation of the sun and stars and from laboratory experiments, which has led him to the conclusion that the so-called elements of the chemist are in reality compound bodies. In order that the line of argument followed by Mr. Lockyer may be understood, it will be necessary briefly to refer to the results of previous researches. As a rule, in observing spectra, the substance to be examined is volatilised in a gas flame or by means of sparks from an induction-coil, and the light is allowed to fall on the slit of the spectroscope; the spectrum is then generally one in which the lines run across the entire field, but by interposing a lens between the spark apparatus and the slit of the spectroscope, $\mathrm{Mr}$. Lockyer was enabled to study the various regions of the heated vapour, and thus to establish the fact, already noted by some previous observers, but to which little attention had been paid, that all the lines in the spectrum of the substance volatilised did not extend to equal distances from the poles. He then showed by the aid of this method that in the case of alloys containing different proportions of two metals, if the one constituent were present in very small quantity, its spectrum was reduced to its simplest form, the line or lines longest in the spectrum of the pure substance alone appearing, but that on increasing the amount of this constituent its other lines gradually appeared in the order of their lengths in the spectrum of the pure substance. Similar observations were made with compound bodies. It was also noticed that the lines furnished by a particular substance varied not only in length and number, but also in brightness and thickness, according to the relative amount present. Armed with these facts, and with the object of uitimately ascertaining, more definitely than has hitherto been possible, which of the elements are present in the sun, Mr. Lockyer, about four years ago, commenced the preparation of a map of a particular region of the spectra of the metallic elements, for comparison with the map of the same region of the solar spectrum. For this purpose about 2,000 photographs of spectra of all the various metallic elements have been taken, and, in addition, more than I00,000 eye observations hare been made. As it is almost impossible to obtain pure substances, the photo graphs have been carefully compared, in order to elimi nate the lines due to impurities; the absence of a par ticular element as impurity being regarded as proved if its longest and strongest line was absent from the photograph of the element under examination. The result of all this labour, Mr. Lockyer states, is to show that the hypothesis that identical lines in different spectra are due to impurities is not sufficient, for he finds short line coincidences between the spectra of many metals in which the freedom from mutual impurity has been demonstrate 1 by the absence of the longest lines. He then adds that, five years ago, he pointed out that there are many facts and many trains of thought suggested by solar and stella! physics which point to another hypothesis-namely, that the elements themselves, or, at all events, some of them, are compound bodies. Thus it would appear that the hotter a star the more simple is its spectrum; for the brightest, and therefore probably the hottest stars, such as Sirius, furnish spectra showing only very thick hydrogen lines and a few very thin metallic lines, characteristic of elements of low atomic weight, while the cooler stars, such as our sun, are shown by their spectra to contain a much larger number of metallic elements than stars such as Sirius, but no non-metallic elements; and the coolest stars furnish fluted band-spectra characteristic of compounds of metallic with non-metallic elements and of non-metallic elements. These facts appear to meet with a simple explanation if it be supposed that as the temperature increases the compounds are first broken up into their constituent "elements," and that these "elements" then undergo dissociation or decomposition into 